\title{
Evaluation of the preventative effects exerted by Lactobacillus fermentum in an experimental model of septic shock induced in mice
}

\author{
Belén Arribas ${ }^{1}$, Maria Elena Rodríguez-Cabezas ${ }^{1}$, Mònica Comalada ${ }^{1}$, Elvira Bailón ${ }^{1}$, Desireé Camuesco ${ }^{1}$, \\ Mónica Olivares $^{2}$, Jordi Xaus ${ }^{2,3}$, Antonio Zarzuelo ${ }^{1}$ and Julio Gálvez ${ }^{1}$ * \\ ${ }^{1}$ Department of Pharmacology, Centro de Investigación Biomédica en Red de Enfermedades Hepáticas y Digestivas (CIBEREHD), \\ University of Granada, Granada, Spain \\ ${ }^{2}$ Department of Immunology and Animal Sciences, Puleva Biotech SA, Granada, Spain \\ ${ }^{3}$ Department of Drug Development and Clinical Research, Palau Pharma, Barcelona, Spain
}

(Received 8 February 2008 - Revised 13 March 2008 - Accepted 25 March 2008 - First published online 29 April 2008)

The preventative effects of the probiotic Lactobacillus fermentum CECT5716 were evaluated in the lipopolysaccharide (LPS) model of septic shock in mice. The probiotic was administered suspended in drinking water at the final concentration of $10^{8}$ colony-forming units $/ \mathrm{ml}$ for 2 weeks before the induction of an endotoxic shock by an intraperitoneal injection of LPS $(400 \mu \mathrm{g} / 200 \mu \mathrm{l}$ per mouse). Blood and different organs were collected after $24 \mathrm{~h}$ to evaluate the severity of the endotoxic shock and the preventative effects of the probiotic. L. fermentum reduced TNF- $\alpha$ levels in blood, which promotes the major alterations observed during septic shock, as well as the infiltration of activated neutrophils into the lungs. Furthermore, free radical overproduction and oxidative stress were associated with a significant decrease in hepatic glutathione levels in septic mice, and with an excessive NO production attributed to the induction of the inducible isoform of NO synthase (iNOS). In fact, hepatic glutathione levels were significantly increased in the group of mice receiving the probiotic, and the increased iNOS expression both in the colon and lungs was down-regulated in those mice treated with L. fermentum. Finally, pre-treatment with L. fermentum may also exert its protective action modulating the expression of different cytokines in splenocyte-derived T cells such us IL-2, IL-5, IL-6 or IL-10. In conclusion, pre-treatment with $L$. fermentum may exert its protective action against LPS-induced organ damage in mice by a combination of several actions including its antioxidant properties and by reduction of the synthesis of the pro-inflammatory TNF- $\alpha$ and IL-6.

Lactobacillus fermentum: Lipopolysaccharide septic shock: Mice: Cytokines

The gastrointestinal tract plays a key role in the control of the immune response, in addition to its primary function in the digestion and absorption of nutrients. First, it acts as a barrier against antigens from micro-organisms and food and, second, contains the gut-associated lymphoid tissues, which are the largest collection of lymphoid tissues in the body. The gutassociated lymphoid tissues are responsible for the main production and release of polymeric $\operatorname{IgA}$ in the body in order to defend mucosal surfaces from environmental microbes ${ }^{(1)}$. The establishment of normal bacterial populations is very important to prevent overgrowth of potential pathogens as well as to contribute to the adequate maturation of the immune system, since misbalances in the microbiota composition have been consistently associated with several patho$\operatorname{logies}{ }^{(2)}$. In consequence, the administration of probiotics, prebiotics or their association (symbiotics) has emerged as an interesting approach to modulate intestinal microbiota.

Probiotics are defined as living micro-organisms that upon ingestion in adequate amounts confer a health benefit to the host beyond inherent general nutrition ${ }^{(3)}$. Although probiotic pharmaceutical formulations are nowadays a common way to administer probiotics, it would be better to incorporate them into the diet through dairy products or other fermented foods. Classically, it has been considered that the beneficial effects exerted by probiotics are achieved due to their ability to colonise the human gastrointestinal tract, thus inducing changes in the composition of the normal intestinal microflora and influencing the immune system. It is evident that most of the beneficial effects reported for probiotics are related to intestinal conditions, such as lactose (or food) intolerance, acute diarrhoea or inflammatory bowel disease ${ }^{(4,5)}$. However, the use of probiotics against systemic immune conditions has also been reported. In fact, Olivares et al. have reported that dietary deprivation of fermented foods could induce a decrease in the innate immune response, which can be effectively counteracted by the ingestion of probiotics ${ }^{(6)}$. Moreover, it has been speculated, both in humans and in experimental models, that inflammation associated with rheumatoid arthritis may be modulated by the use of probiotics ${ }^{(7-10)}$. Furthermore, the effects of probiotics have been studied in the prevention and treatment of atopic disease ${ }^{(11,12)}$. The probiotic administration using a preventative protocol showed a higher efficacy than in a therapeutic approach, most probably due to probiotics exerting their beneficial effects by improving mucosal 
barrier function and enhancing both specific and non-specific immune responses ${ }^{(13,14)}$. However, even though the results obtained after probiotic treatment in both human subjects and experimental animals are promising, it is clear that all probiotics are not equally beneficial, each bacteria may have particular mechanisms of action, and host characteristics may also determine which probiotic species and even strains may be optimal. Supporting this, several studies have shown that not all probiotics exert the same intestinal anti-inflammatory effects in experimental models of intestinal inflammation $^{(15,16)}$. For this reason, it is necessary to test each new probiotic strain to better characterise its safety profile and potential use in the treatment of altered immune conditions.

Sepsis is a generalised and exacerbated and not properly regulated inflammatory response to bacterial translocation, which frequently appears as a secondary complication to a marked depression of the cell-mediated immune response, as it may occur in patients suffering from severe trauma ${ }^{(17)}$. The exact mechanisms involved in this immune dysregulation are not completely understood, although an enhanced generation of inflammatory mediators, including cytokines, chemokines, adhesion molecules, reactive oxygen and nitrogen species, from activated immune cells such as macrophages and polymorphonuclear cells, seems to play a key role ${ }^{(18)}$. The release of lipopolysaccharide (LPS) from bacteria and its recognition by host cells are generally thought to be the initial events in the development of sepsis, thus triggering the inflammatory reaction that may subsequently result in multiple organ dysfunction syndrome associated with failure in different tissues, including lung, liver and brain, and frequently leading to death. Also, an increased permeability of the intestinal barrier has been reported in sepsis ${ }^{(19)}$. There is controversy whether the increased permeability and the subsequent translocation of the gut bacteria are the cause or a consequence of the initial inflammatory response. Anyway, the translocated bacteria could boost the exacerbated inflammatory condition. The incidence of sepsis is still increasing, with high rates of mortality (up to $70 \%$ ) despite the use of life-support therapies ${ }^{(20)}$. Therefore, more efficient strategies are required to modulate the inflammation and also to reduce the bacterial translocation occurring in sepsis, and, for this purpose, dietary manipulation through probiotic administration would be of great interest. Considering how probiotics exert their beneficial effect as well as the severity and the rapid onset of sepsis, preventative dietary administration of probiotic seems to be the most adequate protocol to perform these studies.

The aim of the present study was to evaluate the preventative effects of the probiotic Lactobacillus fermentum CECT5716 in a model of septic shock in mice induced by LPS, since, in previous studies, this probiotic has been shown to be able to modulate some of the potential mechanisms of sepsis. In this regard, immunomodulatory properties have been described for this probiotic, since it is able to enhance the Th1 response ${ }^{(21)}$ and increase the IgA concentration in faeces helping the blockage and elimination of translocated bacteria ${ }^{(22)}$. Furthermore, this strain has been described as displaying anti-infective properties against different pathogenic micro-organisms through different mechanisms, including inhibition of the adhesion to epithelial cells, secretion of anti-microbial compounds and improvement of the intestinal barrier function by inducing the expression of intestinal mucins ${ }^{(23)}$. Furthermore, several strains of this probiotic have been reported to display antioxidant properties that could account for their beneficial effects since oxidative stress is associated with inflammatory conditions, including sepsis or colonic inflammation $^{(24-28)}$. All these data make L. fermentum CECT5716 an interesting candidate to evaluate its effects on altered immune response conditions, such as sepsis.

\section{Materials and methods}

\section{Reagents}

All chemicals, including LPS from Escherichia coli serotype 055:B5, were obtained from Sigma Chemical (Madrid, Spain), unless otherwise stated.

\section{Preparation and administration of the probiotic}

L. fermentum CECT5716 was provided by Puleva Biotech (Granada, Spain) and was normally grown in de Man, Rogosa and Sharpe (MRS) media at $37^{\circ} \mathrm{C}$ in anaerobic conditions using the Anaerogen system (Oxoid, Basingstoke, Hants, UK). For probiotic treatment, bacteria were suspended in a sterile PBS solution $\left(10^{9}\right.$ colony-forming units $\left./ \mathrm{ml}\right)$ and stored at $-80^{\circ} \mathrm{C}$ until usage.

\section{Experimental design}

Male BALB/c mice weighing 20-22 g were obtained from the Laboratory Animal Service of the University of Granada (Granada, Spain), housed in Makrolon cages and maintained in an air-conditioned atmosphere with a $12 \mathrm{~h}$ light-dark cycle, and provided with free access to tap water and food. All manipulations with animals were in accordance with the 'Guide for the Care and Use of Laboratory Animals' as promulgated by the National Institute of Health. The mice were randomly assigned to three groups ( $n$ 10); two of them (healthy and control groups) received tap water and the other (treated group) received the probiotic suspended in drinking water at the final concentration of $10^{8}$ colony-forming units $/ \mathrm{ml}$ and daily prepared. Food and water intake was recorded daily for all groups. At 2 weeks after starting the experiment, endotoxic shock was induced in treated and control mice with an intraperitoneal injection of LPS $(400 \mu \mathrm{g} / \mathrm{mouse})$ to a final volume of $200 \mu \mathrm{l}$; healthy mice received sterile saline. Preliminary assays revealed that this dose of LPS did not induce the death of any mouse in the following $24 \mathrm{~h}$. At $24 \mathrm{~h}$ after injection, mice were anaesthetised with halothane, blood samples were taken from the retro-orbital venous plexus, and then the mice were killed immediately. The following tissues were quickly removed and weighed: spleen, lungs, liver, kidneys and colon. Colonic specimens were frozen at $-80^{\circ} \mathrm{C}$ for myeloperoxidase (MPO) activity and inducible NO synthase (iNOS) expression. Liver samples were frozen in $1 \mathrm{ml}$ TCA $(50 \mathrm{~g} / \mathrm{l})$ for total glutathione content determination. One of the lungs was immediately processed for the measurement of TNF- $\alpha$ levels and the other was frozen at $-80^{\circ} \mathrm{C}$ for MPO activity and iNOS expression. All biochemical measurements were completed within 1 week from the time of sample collection and were performed in duplicate. 


\section{Biochemical determinations}

MPO activity was measured in colonic tissue as previously described $^{(29)}$; the results were expressed as MPO units/g wet tissue; one unit of MPO activity was defined as that degrading $1 \mu \mathrm{mol} \mathrm{H}_{2} \mathrm{O}_{2} / \mathrm{min}$ at $25^{\circ} \mathrm{C}$. Total glutathione content was quantified in liver with the recycling assay described by Anderson ${ }^{(30)}$, and the results were expressed as $\mathrm{nmol} / \mathrm{g}$ wet tissue. Lung samples for TNF- $\alpha$ determination were immediately weighed, minced on an ice-cold plate and suspended in a tube with $10 \mathrm{mM}$-sodium phosphate buffer $(\mathrm{pH} 7 \cdot 4)(1: 5, \mathrm{w} / \mathrm{v})$. The tubes were placed in a shaking water-bath $\left(37^{\circ} \mathrm{C}\right)$ for $20 \mathrm{~min}$ and centrifuged at $9000 \mathrm{~g}$ for $30 \mathrm{~s}$ at $4^{\circ} \mathrm{C}$; the supernatant fractions were frozen at $-80^{\circ} \mathrm{C}$ until assay. TNF- $\alpha$ was quantified by ELISA (Amersham Pharmacia Biotech, Little Chalfont, Bucks, UK) and the results were expressed as $\mathrm{pg} / \mathrm{g}$ wet tissue. Colonic and lung specimens were also used for protein extraction to evaluate iNOS expression by Western blotting, which was performed as described elsewhere ${ }^{(31)}$. Blood samples were centrifuged $(1500 \mathrm{rpm}$ for $10 \mathrm{~min}$ ), and plasma TNF- $\alpha$ was quantified by ELISA (Amersham Pharmacia Biotech) and the results were expressed as $\mathrm{pg} / \mathrm{ml}$.

\section{Cytokine production in splenocytes}

In order to obtain primary lymphocyte cultures, spleens were immediately disaggregated in Dulbecco's modified Eagle's medium plus $1 \%$ penicillin/streptomycin after collection, centrifuged (1500 rpm; $5 \mathrm{~min}$ ), and erythrocytes were lysed with a lysis buffer $\left(\mathrm{NH}_{4} \mathrm{Cl}(1.7 \mathrm{~mol} / \mathrm{l}), \mathrm{KHCO}_{3}(0.12 \mathrm{~mol} / \mathrm{l})\right.$, ethylenediamine-tetra-acetic $(9 \mathrm{mmol} / \mathrm{l}))$ for $30 \mathrm{~min}$ at $4^{\circ} \mathrm{C}$. Resting cells were counted using a haemocytometer and cultured to perform proliferation and stimulation assays in current culture medium (Dulbecco's modified Eagle's medium $+10 \%$ fetal bovine serum). Cells were incubated at $37^{\circ} \mathrm{C}$ in a humidified $5 \% \mathrm{CO}_{2}$ atmosphere.

Spleen-derived lymphocytes were cultured in six-well plates $\left(10 \times 10^{6}\right.$ cells/well $)$ in $2 \mathrm{ml}$ media and stimulated with concanavalin A (Con A; $5 \mu \mathrm{g} / \mathrm{ml}$ ). Supernatant fractions were collected after $48 \mathrm{~h}$ and frozen until ELISA analysis. Cytokine production was measured with commercial murine ELISA kits (Cytosets ${ }^{\mathrm{TM}}$; Biosource International, Nivelles, Belgium) following the manufacturer's protocol. Total RNA was isolated using TRIzol@ Reagent (Gibco-BRL, Carlsbad, CA, USA) following the manufacturer's protocol. cDNA was synthesised using a First-Strand cDNA Synthesis Kit (Amersham Biosciences). The primer sequences were: IL-2 (forward
5'-CTTCAAGCTCCACTTCAAGCT-3', reverse 5'-CCATCTCCTCAGAAAGTCCACC-3'); IL-5 (forward 5'-TCAGGGAATAGGCACACTGG-3 ${ }^{\prime}$, reverse $5^{\prime}$-CTCCGTCTTTCTTCTCCACAC-3'); IL-6 (forward 5'-TGATGGATGCTACCAAACTGG- $3^{\prime}$, reverse $5^{\prime}$-AGGAGAGCATTGGAAATTGG-3'); IL-10 (forward 5'-TGCCTGCTCTTACTGACTGG, reverse $5^{\prime}$-TCATTTCCGATAAGGCTTGG); $\beta$-actin (forward 5'-AATCGTGCGTGACATCAAAG- $3^{\prime}$, reverse $5^{\prime}$-ATGCCACAGGATTCCATACC $\left.-3^{\prime}\right)$. The PCR was performed as described previously ${ }^{(32)}$ but in this case the cycles used were: thirty-two cycles for IL-2, thirty-five cycles for IL-5 and IL-10, thirty cycles for IL-6 and twenty-five cycles for $\beta$-actin.

\section{Statistics}

All results are expressed as the mean values with their standard errors. Data were analysed by one-way ANOVA and post hoc least-significance tests. All statistical analyses were carried out with the Statgraphics 5.0 software package (StatPoint, Inc., Herndon, VA, USA) with differences considered significant set at $P<0 \cdot 05$.

\section{Results}

The preventative probiotic administration to mice for 2 weeks before septic shock induction did not affect body-weight gain compared with untreated groups (data not shown), and no sign of toxic effects was observed, similarly to that previously reported for rats and mice ${ }^{(21,27,33)}$. After 2 weeks of probiotic consumption, mice received an intraperitoneal injection of saline or a sub-lethal dose of $400 \mu \mathrm{g}$ LPS, and, $8 \mathrm{~h}$ after LPS administration, mice showed evident symptoms of endotoxic shock, similar to those described previously ${ }^{(34)}$, including decreased motor activity, ruffled fur and ocular exudates. All mice survived $24 \mathrm{~h}$ after LPS injection, when they were killed after exsanguination. Macroscopic tissue modifications were observed as a consequence of the septic shock. Significant increases in colon weight:length ratio and in spleen and lung weights were observed in the control group when compared with healthy mice $(P<0 \cdot 05$; Table 1$)$, whereas no significant modification was observed in the weights of liver and kidneys (Table 1). The probiotic treatment resulted in a significant improvement in these tissue modifications, showing similar values to those in the healthy group (Table 1).

The beneficial effects exerted by the probiotic pre-treatment in this experimental model of septic shock were also confirmed biochemically. One of the key cytokines involved in

Table 1. Effects of probiotic treatment on tissue weights in lipopolysaccharide-induced septic shock in mice (Mean values with their standard errors for ten mice per group)

\begin{tabular}{|c|c|c|c|c|c|c|c|c|c|c|}
\hline \multirow[b]{2}{*}{ Group } & \multicolumn{2}{|c|}{$\begin{array}{l}\text { Liver (mg/g body } \\
\text { mass) }\end{array}$} & \multicolumn{2}{|c|}{$\begin{array}{l}\text { Kidneys (mg/g } \\
\text { body mass) }\end{array}$} & \multicolumn{2}{|c|}{ Colon (mg/cm) } & \multicolumn{2}{|c|}{$\begin{array}{l}\text { Spleen (mg/g } \\
\text { body mass) }\end{array}$} & \multicolumn{2}{|c|}{$\begin{array}{l}\text { Lungs (mg/g } \\
\text { body mass) }\end{array}$} \\
\hline & Mean & SEM & Mean & SEM & Mean & SEM & Mean & SEM & Mean & SEM \\
\hline Healthy & $49 \cdot 4$ & $1 \cdot 6$ & $18 \cdot 2$ & 0.6 & $22 \cdot 5$ & 0.9 & $3 \cdot 5$ & $0 \cdot 2$ & $6 \cdot 8$ & 0.1 \\
\hline Control & $51 \cdot 3$ & $2 \cdot 1$ & $20 \cdot 2$ & 1.4 & $26 \cdot 1^{*}$ & $1 \cdot 1$ & $4 \cdot 4^{\star}$ & $0 \cdot 1$ & $7 \cdot 4^{\star}$ & 0.2 \\
\hline Lactobacillus fermentum & $50 \cdot 4$ & $1 \cdot 0$ & $19 \cdot 1$ & 0.9 & $23 \cdot 1 \dagger$ & 0.9 & $3.6 \dagger$ & 0.2 & $6.9+$ & 0.2 \\
\hline
\end{tabular}

${ }^{*}$ Mean value was significantly different from that of the healthy group $(P<0.05)$.

† Mean value was significantly different from that of the control group $(P<0.05)$. 
sepsis is TNF- $\alpha$, the systemic release of which induces increased vascular permeability and disseminated intravascular coagulation, responsible for the state of shock ${ }^{(35)}$. TNF- $\alpha$ levels were significantly increased $24 \mathrm{~h}$ after intraperitoneal administration of LPS to mice, both in the plasma and lungs, in comparison with normal mice. The administration of $L$. fermentum for 2 weeks before LPS injection resulted in a significantly lower $\mathrm{TNF}-\alpha$ production when compared with untreated control mice (Fig. 1). In addition, sepsis promotes the activation and migration of leucocytes into various organs ${ }^{(35)}$, one of the most common events being the infiltration of activated neutrophils into lung tissue ${ }^{(36)}$. Thus a higher neutrophil influx was also observed in the lungs of control LPS-treated mice, evidenced by the 10-fold increase in lung MPO activity in comparison with healthy animals $(P<0.01)$ (Table 2). However, when this enzyme activity was evaluated in colonic tissue, no significant modification was observed among groups (Table 2), although macroscopic alteration was observed in this organ. The pre-treatment with the probiotic partially counteracted the increased lung MPO activity observed in control mice $(P<0.05$; Table 2). Furthermore, sepsis is associated with an enhanced production of reactive oxygen metabolites, which cause oxidative damage in different organs, leading to multiple organ dysfunction ${ }^{(37)}$. In the present study, free radical overproduction was associated with a significant decrease in hepatic glutathione levels in septic mice $(P<0.01 v$. healthy group; Table 2$)$, which was significantly
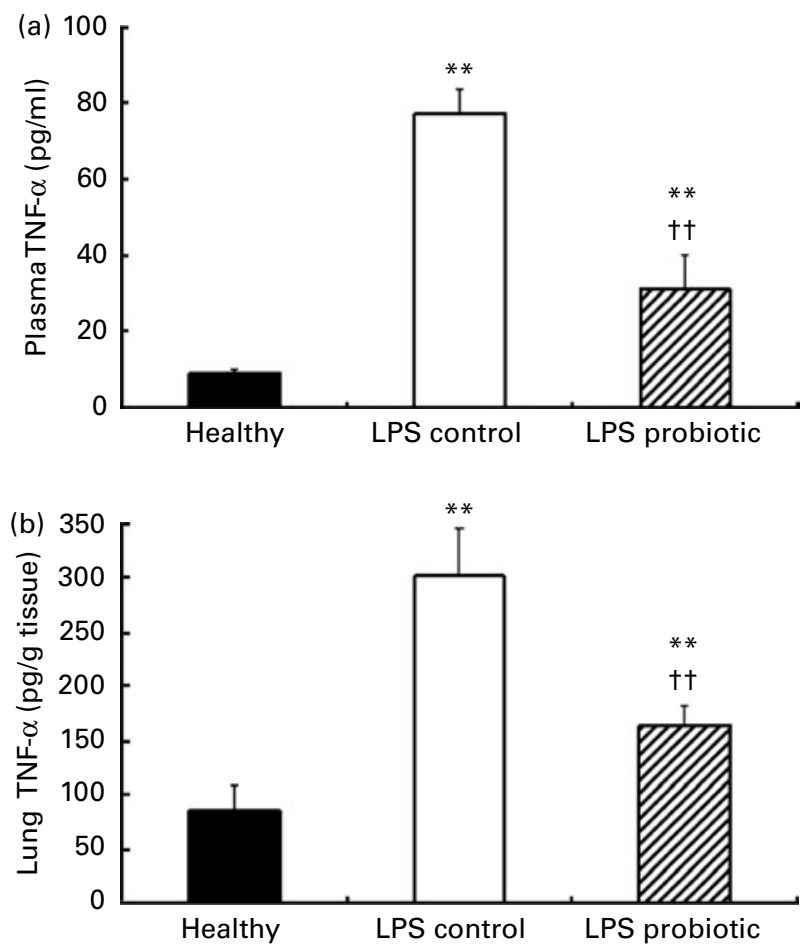

Fig. 1. Effect of Lactobacillus fermentum probiotic on TNF- $\alpha$ production in lipopolysaccharide (LPS)-induced septic shock in mice. Probiotic pretreatment inhibits this cytokine production in the plasma (a) and lungs (b). The concentrations of the cytokine were analysed by ELISA. Values are means $(n 10)$, with standard errors represented by vertical bars. ** Mean value was significantly different from that of the healthy group $(P<0.01)$. †† Mean value was significantly different from that of the control group $(P<0.01)$. increased in the group of mice receiving the probiotic $(P<0.05 v$. control group; Table 2$)$, although probiotic pre-treatment was not able to restore the values obtained in healthy animals. Moreover, an increased iNOS expression after LPS administration was evidenced by Western blot both in the colon and lungs of septic control mice when compared with the healthy group, and this was down-regulated in those mice treated with L. fermentum (Fig. 2).

To further evaluate the effects of the probiotic treatment on the altered immunological response after LPS administration, the expression of different Th1, Th2 and Th3 cytokines (IL-2, IL-5, IL-6 and IL-10) in Con A-stimulated splenocytes was analysed. RT-PCR and/or ELISA analysis revealed that Con A-stimulated cytokine expression was altered in the splenocytes from septic mice (Fig. 3). In this sense, a clear increased expression of IL-2, IL-5 and IL-6 was observed in the control mice in comparison with healthy ones, while a decreased expression of the regulatory Th3 cytokine IL-10 was detected. Probiotic administration reduced the expression of the pro-inflammatory cytokines and restored the expression of IL-10 to those levels observed in Con A-stimulated lymphocytes obtained from healthy mice.

\section{Discussion}

Sepsis is a systemic inflammatory condition commonly caused by bacterial infections, which is associated with multiple organ failure and has a poor prognosis due to the lack of an effective treatment ${ }^{(38)}$. Bacterial pathogens and their products trigger the inflammatory response by transcriptional activation of inflammatory genes, leading to an excessive and uncontrolled release of a large number of inflammatory mediators, including cytokines, chemokines, adhesion molecules, reactive oxygen and nitrogen species. Recent studies have revealed that the incidence of sepsis is still increasing ${ }^{(20)}$, and, in consequence, more efficient strategies to modulate the inflammation in sepsis are needed.

Although a general multiple organ failure has been observed in humans, mainly affecting the lungs, liver, kidneys and even the brain ${ }^{(39)}$, in our experimental settings only the colon, lungs and spleen were enlarged due to inflammation or over-activation of the immune response, in the latter. Furthermore, an alteration of liver function was also evidenced since a significant depletion of the glutathione levels occurred. Other organs were not affected, maybe due to the fact that we evaluated the sepsis only $24 \mathrm{~h}$ after induction.

Several biochemical and immunological mechanisms have been proposed to be responsible for the alterations observed during sepsis. In this sense, a critical role of TNF- $\alpha$ in the development of LPS-mediated shock in mice has been consistently reported, since an excess of this cytokine promotes the major alterations observed during septic shock, including vasodilatation, impaired coagulation and fibrinolysis ${ }^{(35)}$. In addition, an altered expression of other Th1 and Th2 cytokines such as interferon $\gamma$, IL-2, IL-4 or IL-5 has also been described ${ }^{(39-41)}$. IL-6, together with TNF- $\alpha$, is also considered one of the most important mediators in the pathogenesis of sepsis and septic shock. It displays potent biological effects, including stimulation of B- and T-lymphocytes, and induction of the hepatic acutephase response ${ }^{(42)}$, thus promoting tissue injury, multiple organ failure and death ${ }^{(43,44)}$. Other mechanism involved in 
Table 2. Effects of probiotic treatment on lung myeloperosidase (MPO) activity and hepatic glutathione (GSH) content in lipopolysaccharide-induced septic shock in mice

(Mean values with their standard errors for ten mice per group)

\begin{tabular}{|c|c|c|c|c|c|c|}
\hline \multirow[b]{2}{*}{ Group } & \multicolumn{2}{|c|}{$\begin{array}{l}\text { Colonic MPO activity } \\
\text { (units/g tissue) } \ddagger\end{array}$} & \multicolumn{2}{|c|}{$\begin{array}{l}\text { Lung MPO activity } \\
\text { (units/g tissue) } \ddagger\end{array}$} & \multicolumn{2}{|c|}{$\begin{array}{l}\text { Hepatic GSH content } \\
\text { (nmol/g tissue) }\end{array}$} \\
\hline & Mean & SEM & Mean & SEM & Mean & SEM \\
\hline Healthy & $16 \cdot 3$ & $2 \cdot 5$ & $2 \cdot 3$ & 0.4 & 7091 & 570 \\
\hline Control & $22 \cdot 8$ & $3 \cdot 5$ & $23 \cdot 2^{*}$ & $3 \cdot 0$ & 2703 & 184 \\
\hline Lactobacillus fermentum & $21 \cdot 8$ & 2.9 & $15.4 \dagger$ & $3 \cdot 0$ & $3198^{*} \dagger$ & 137 \\
\hline
\end{tabular}

* Mean value was significantly different from that of the healthy group $(P<0.05)$.

† Mean value was significantly different from that of the control group $(P<0.05)$.

$\ddagger$ One unit of MPO activity was defined as that degrading $1 \mu \mathrm{mol}_{2} \mathrm{O}_{2} / \mathrm{min}$ at $25^{\circ} \mathrm{C}$

the pathogenesis of sepsis is the excessive production of $\mathrm{NO}$, most probably derived from the increased expression of iNOS $^{(45)}$. Furthermore, it is well reported that the generalised inflammatory response that occurs in sepsis is associated with an enhanced generation of reactive oxygen metabolites, mainly derived from neutrophil activity, that also contributes to multiple organ dysfunction ${ }^{(46)}$.

As expected, LPS-administered mice showed an alteration of the cytokine profile production including increased levels of TNF- $\alpha$, IL-2, IL-5 and IL-6 and a reduced expression of the regulatory cytokine IL-10. The involvement of NO and reactive oxygen metabolites was confirmed by an enhanced iNOS expression in the lungs and colon, and a glutathione depletion in the liver, respectively. Moreover, a neutrophil infiltration in the lungs was also evident, shown by augmented MPO activity.

The present study shows for the first time that feeding mice with the probiotic L. fermentum CECT5716 clearly prevented septic shock conditions by ameliorating the altered production of inflammatory mediators. Thus $L$. fermentum was able to down-regulate the increased levels of TNF- $\alpha$ both in the plasma and lungs. The ability of this probiotic to reduce

(a)

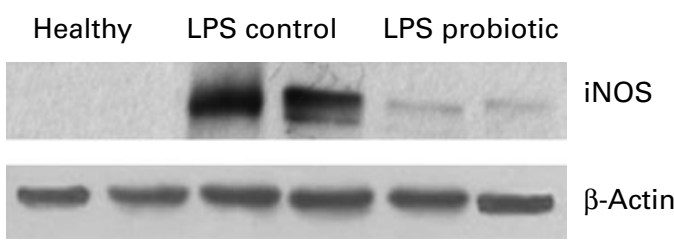

(b)

Healthy LPS control LPS probiotic
iNOS
B-Actin

Fig. 2. Effect of Lactobacillus fermentum probiotic on lung (a) and colonic (b) inducible NO synthase (iNOS) expression in lipopolysaccharide (LPS)induced septic shock in mice. iNOS expression was analysed by Western blot using tissue homogenates as described in Materials and methods. In each lane $150 \mu \mathrm{g}$ protein were loaded. $\beta$-Actin expression was used as the control for loading and transfer.
TNF- $\alpha$ production in inflammatory conditions has been previously reported in an experimental model of rat colitis ${ }^{(27)}$. The beneficial effects showed by $L$. fermentum can be derived from an improvement in the altered immune response induced by LPS, since there is a reduction in the expression of the proinflammatory cytokines IL-2, IL-5, IL-6 as well as an increase of IL-10 in Con A-stimulated splenocytes. Similarly to other probiotics, L. fermentum was more efficient at modulating IL-10 than other cytokines, including IL-2. This can be

(a) Healthy LPS control LPS probiotic

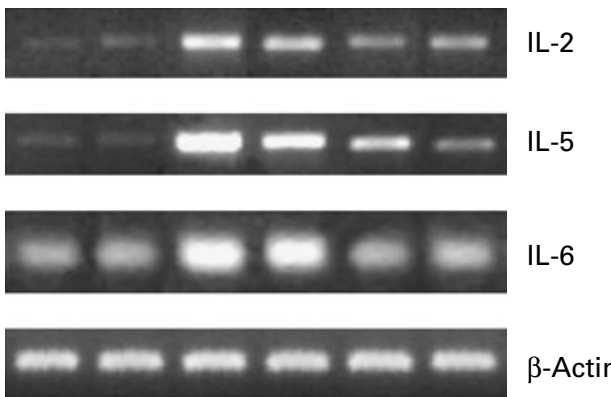

(b)

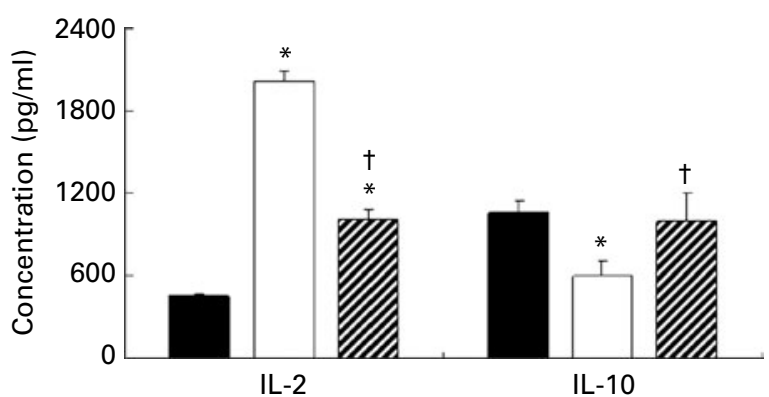

Fig. 3. (a) Effect of Lactobacillus fermentum probiotic on the expression of cytokines in concanavalin A (Con A)-activated T-lymphocytes from mice after lipopolysaccharide (LPS)-induced septic shock. Splenocytes were incubated with Con A during $48 \mathrm{~h}$ and the expressions of cytokines in cells were assessed by RT-PCR. (b) Effects of probiotic treatment on IL-2 and IL-10 secretion in Con A-stimulated splenocytes from mice with LPS-induced septic

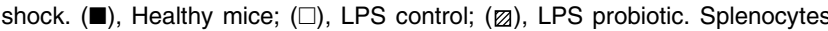
were incubated with Con A during $48 \mathrm{~h}$ and the concentration of the cytokine in the supernatant fraction was analysed by ELISA. Values are means ( $n 10)$, with standard errors represented by vertical bars. * Mean value was significantly different from that of the healthy group $(P<0.05)$. † Mean value was significantly different from that of the control group $(P<0.05)$. 
explained by a direct effect of the probiotic in inducing IL-10 expression in macrophages and lymphocytes as previously described $^{(21)}$, while the effect on IL-2 might be an indirect effect mediated both by the increased expression of IL-10 and the reduction on the inflammatory process exerted by the probiotic treatment.

The likely consequences of the immunomodulatory actions of $L$. fermentum in septic mice could be the amelioration of the tissue damage and inflammation induced by LPS. The latter was confirmed in the present study since MPO activity was partially reduced in the lungs from mice treated with the probiotic when compared with septic animals. Moreover, a reduction in the lung and colon iNOS expression was observed in probiotic-fed mice. The ability of this probiotic to inhibit iNOS expression in vivo has been previously reported to occur in the rat inflamed intestine after trinitrobenzenesulfonic acid instillation ${ }^{(33)}$.

In addition to its immunomodulatory properties, other mechanisms could contribute to the beneficial effects displayed by $L$. fermentum to prevent mice from sepsis. In this regard, the probiotic also partially preserved the content of the antioxidant peptide glutathione in the liver, thus preventing the deleterious effects that reactive oxygen metabolites may induce once they are produced and released in this inflammatory condition. In fact, this lactobacilli strain has been reported to produce and release glutathione as well as its precursor, the dipeptide $\gamma$-Glu-Cys, displaying both compounds' free radical scavenger properties ${ }^{(27)}$, which could counteract the intense oxidative stress situation in LPSinduced septic shock in mice. It is important to point out that the antioxidant effects exerted by $L$. fermentum could also collaborate in the inhibition of tissue neutrophil infiltration, as observed in the present study, since free radical generation causes a vicious circle that promotes additional infiltration of neutrophils into inflamed tissue, which in turn produce a large amount of free radicals that actively participate in the perpetuation of the inflammatory response ${ }^{(47)}$.

In conclusion, the dietary consumption of probiotics and the modulation of the intestinal microbiota could exert beneficial effects on potentially immune-related pathologies, as has been demonstrated in the present study with L. fermentum CECT5716 in the LPS model of septic shock in mice. Although the therapeutic use of probiotics could be of potential interest in the management of clinical sepsis, it is relevant to note that this process has a fast onset and a high severity, making their effective application difficult in many cases. However, probiotic administration, following a preventative approach, could be useful in those cases of programmed surgical interventions or other pathologies in where septicaemia frequently occurs as a secondary complication. Anyway, both efficacy and safety of probiotic treatment should be carefully tested in well-designed and conducted clinical trials.

Recently, some disappointing results have been reported after administration of a specific mixture of probiotics in the management of critically ill patients suffering from pancreatitis and some concerns have arisen about the clinical use of probiotics in those patients ${ }^{(48)}$. Nevertheless, some probiotic strains have been tested in immunocompromised patients suffering from HIV without major side effects ${ }^{(49-51)}$. However, every probiotic strain is different, and for this reason they have to be individually checked, not only for their efficacy but also for safety reasons. We should not be disappointed about the above-mentioned undesirable effects, and carry on the research into the potential clinical uses of probiotics.

\section{Acknowledgements}

There is no conflict of interest to declare by any of the authors. All authors have contributed to the conception and design of the experiment, acquisition of the data and their subsequent analysis and interpretation. Similarly, all authors have been involved in the revising the paper critically and have approved the final version of the paper. J. G. supervised in all phases. The study was supported by the Spanish Ministry of Science and Technology (SAF2005-03 199), with funds from the European Union, and by Junta de Andalucia (CTS 164). M. C. is a recipient of the Ramon y Cajal Programme from the Spanish Ministry of Science and Technology; E. B. is a recipient from the Spanish Ministry of Education and Science. Centro de Investigación Biomédica en Red de Enfermedades Hepáticas y Digestivas (CIBEREHD) is funded by the Instituto de Salud Carlos III.

\section{References}

1. Forchielli ML \& Walker WA (2005) The role of gut-associated lymphoid tissues and mucosal defence. Br J Nutr 93, Suppl. 1, $\mathrm{S} 41-\mathrm{S} 48$.

2. Asher MI, Montefort S, Björkstén B, Lai CK, Strachan DP, Weiland SK \& Williams H (2006) Worldwide time trends in the prevalence of symptoms of asthma, allergic rhinoconjunctivitis, and eczema in childhood: ISAAC Phases One and Three repeat multicountry cross-sectional surveys. Lancet $\mathbf{3 6 8}$, 733-743.

3. Guarner F \& Schaafsma GJ (1998) Probiotics. Int J Food Microbiol 39, 237-238.

4. Ouwehand AC, Salminen S \& Isolauri E (2002) Probiotics: an overview of beneficial effects. Antonie Van Leeuwenhoek 82, 279-289.

5. Parvez S, Malik KA, Ah Kang S \& Kim HY (2006) Probiotics and their fermented food products are beneficial for health. J Appl Microbiol 100, 1171-1185.

6. Olivares M, MPaz Díaz-Ropero M, Gómez N, Sierra S, Lara-Villoslada F, Martín R, Miquel Rodríguez J \& Xaus J (2006) Dietary deprivation of fermented foods causes a fall in innate immune response. Lactic acid bacteria can counteract

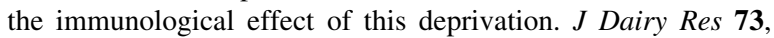
492-498.

7. Malin M, Verronen $P$, Korhonen H, Syväoja EL, Salminen S, Mykkänen H, Arvilommi H, Eerola E \& Isolauri E (1997) Dietary therapy with Lactobacillus GG, bovine colostrum or bovine immune colostrum in patients with juvenile chronic arthritis: evaluation of effect on gut defence mechanisms. Inflammopharmacology $\mathbf{5}, 219-236$.

8. Kato I, Endo-Tanaka K \& Yokokura T (1998) Suppressive effects of the oral administration of Lactobacillus casei on type II collagen-induced arthritis in DBA/1 mice. Life Sci 63, 635-644.

9. Baharav E, Mor F, Halpern M \& Weinberger A (2004) Lactobacillus GG bacteria ameliorate arthritis in Lewis rats. $J$ Nutr 134, 1964-1969.

10. Sheil B, McCarthy J, O'Mahony L, Bennett MW, Ryan P, Fitzgibbon JJ, Kiely B, Collins JK \& Shanahan F (2004) Is the mucosal route of administration essential for probiotic function? 
Subcutaneous administration is associated with attenuation of murine colitis and arthritis. Gut 53, 694-700.

11. Isolauri E, Arvola T, Sütas Y, Moilanen E \& Salminen S (2000) Probiotics in the management of atopic eczema. Clin Exp Allergy 30, 1604-1610.

12. Rosenfeldt V, Benfeldt E, Nielsen SD, Michaelsen KF, Jeppesen DL, Valerius NH \& Paerregaard A (2003) Effect of probiotic Lactobacillus strains in children with atopic dermatitis. J Allergy Clin Immunol 111, 389-395.

13. Macfarlane GT \& Cummings JH (2002) Probiotics, infection and immunity. Curr Opin Infect Dis 15, 501-506.

14. Vaarala $\mathrm{O}$ (2003) Immunological effects of probiotics with special reference to lactobacilli. Clin Exp Allergy 33, 1634-1640.

15. Shibolet O, Karmeli F, Eliakim R, Swennen E, Brigidi P, Gionchetti P, Campieri M, Morgenstern S \& Rachmilewitz D (2002) Variable response to probiotics in two models of experimental colitis in rats. Inflamm Bowel Dis 8, 399-406.

16. Peran L, Camuesco D, Comalada M, Bailon E, Henriksson A, Xaus J, Zarzuelo A \& Galvez J (2007) A comparative study of the preventative effects exerted by three probiotics. Bifidobacterium lactis, Lactobacillus casei and Lactobacillus acidophilus, in the TNBS model of rat colitis. J Appl Microbiol 103, 836-844.

17. Ayala A, Lehman DL, Herdon CD \& Chaudry IH (1994) Mechanism of enhanced susceptibility to sepsis following hemorrhage. Interleukin-10 suppression of T-cell response is mediated by eicosanoid-induced interleukin-4 release. Arch Surg 129, 1172-1178.

18. Liu SF \& Malik AB (2006) NF- $\kappa B$ activation as a pathological mechanism of septic shock and inflammation. Am J Physiol Lung Cell Mol Physiol 290, L622-L645.

19. Jørgensen VL, Nielsen SL, Espersen K \& Perner A (2006) Increased colorectal permeability in patients with severe sepsis and septic shock. Intensive Care Med 32, 1790-1796.

20. Yende S \& Angus DC (2007) Long-term outcomes from sepsis. Curr Infect Dis Rep 9, 382-386.

21. Díaz-Ropero MP, Martín R, Sierra S, Lara-Villoslada F, Rodríguez JM, Xaus J \& Olivares M (2007) Two Lactobacillus strains, isolated from breast milk, differently modulate the immune response. J Appl Microbiol 102, 337-343.

22. Olivares M, Díaz-Ropero MP, Sierra S, Lara-Villoslada F, Fonollá J, Navas M, Rodríguez JM \& Xaus J (2007) Oral intake of Lactobacillus fermentum CECT5716 enhances the effects of influenza vaccination. Nutrition 23, 254-260.

23. Olivares M, Díaz-Ropero MP, Martín R, Rodríguez JM \& Xaus J (2006) Antimicrobial potential of four Lactobacillus strains isolated from breast milk. J Appl Microbiol 101, 72-79.

24. Geier MS, Butler RN, Giffard PM \& Howarth GS (2007) Lactobacillus fermentum BR11, a potential new probiotic, alleviates symptoms of colitis induced by dextran sulfate sodium (DSS) in rats. Int J Food Microbiol 114, 267-274.

25. Hung J, Cooper D, Turner MS, Walsh T \& Giffard PM (2003) Cystine uptake prevents production of hydrogen peroxide by Lactobacillus fermentum BR11. FEMS Microbiol Lett 227, 93-99.

26. Kullisaar T, Zilmer M, Mikelsaar M, Vihalemm T, Annuk H, Kairane C \& Kilk A (2002) Two antioxidative lactobacilli strains as promising probiotics. Int J Food Microbiol 72, 215-224.

27. Peran L, Camuesco D, Comalada M, Nieto A, Concha A, Adrio JL, Olivares M, Xaus J, Zarzuelo A \& Galvez J (2006) Lactobacillus fermentum, a probiotic capable to release glutathione, prevents colonic inflammation in the TNBS model of rat colitis. Int $J$ Colorectal Dis 21, 737-746.

28. Songisepp E, Kals J, Kullisaar T, Mändar R, Hütt P, Zilmer M $\&$ Mikelsaar M (2005) Evaluation of the functional efficacy of an antioxidative probiotic in healthy volunteers. Nutr $J \mathbf{4}, 22$.
29. Sánchez de Medina F, Gálvez J, Romero JA \& Zarzuelo A (1996) Effect of quercitrin on acute and chronic experimental colitis in the rat. J Pharmacol Exp Ther 278, 771-779.

30. Anderson ME (1985) Determination of glutathione and glutathione disulfide in biological samples. Methods Enzymol 113, $548-555$.

31. Comalada M, Camuesco D, Sierra S, Ballester I, Xaus J, Gálvez J \& Zarzuelo A (2005) In vivo quercitrin anti-inflammatory effect involves release of quercetin, which inhibits through down-regulation of the NF-kB pathway. Eur J Immunol 35, 584-592.

32. Comalada M, Ballester I, Bailón E, Sierra S, Xaus J, Gálvez J, de Medina FS \& Zarzuelo A (2006) Inhibition of pro-inflammatory markers in primary bone marrow-derived mouse macrophages by naturally occurring flavonoids: analysis of the structure-activity relationship. Biochem Pharmacol 72, 1010-1021.

33. Peran L, Sierra S, Comalada M, et al. (2007) A comparative study of the preventative effects exerted by two probiotics, Lactobacillus reuteri and Lactobacillus fermentum, in the trinitrobenzenesulfonic acid model of rat colitis. Br J Nutr 97, 96-103.

34. Leite MS, Pacheco P, Gomes RN, Guedes AT, Castro-FariaNeto HC, Bozza PT \& Koatz VL (2005) Mechanisms of increased survival after lipopolysaccharide-induced endotoxic shock in mice consuming olive oil-enriched diet. Shock 23, 173-178.

35. Annane D, Bellissant E \& Cavaillon JM (2005) Septic shock Lancet 365, 63-78.

36. Welbourn CR \& Young Y (1992) Endotoxin, septic shock and acute lung injury: neutrophils, macrophages and inflammatory mediators. Br J Surg 79, 998-1003.

37. Salvemini D \& Cuzzocrea S (2002) Oxidative stress in septic shock and disseminated intravascular coagulation. Free Radic Biol Med 33, 1173-1185.

38. Patel GP, Gurka DP \& Balk RA (2003) New treatment strategies for severe sepsis and septic shock. Curr Opin Crit Care 9, 390-396.

39. Hotchkiss RS \& Karl IE (2003) The pathophysiology and treatment of sepsis. N Engl J Med 348, 138-150.

40. Kim GY, Roh SI, Park SK, Ahn SC, Oh YH, Lee JD \& Park YM (2003) Alleviation of experimental septic shock in mice by acidic polysaccharide isolated from the medicinal mushroom Phellinus linteus. Biol Pharm Bull 26, 1418-1423.

41. Hsu CS, Chiu WC, Yeh CL, Hou YC, Chou SY \& Yeh SL (2006) Dietary fish oil enhances adhesion molecule and interleukin-6 expression in mice with polymicrobial sepsis. Br J Nutr 96, 854-860.

42. Barton BE (1996) The biological effects of interleukin 6. Med Res Rev 1, 87-109.

43. Hack CE, De Groot ER, Felt-Bersma RJ, Nuijens JH, Strack Van Schijndel RJ, Eerenberg-Belmer AJ, Thijs LG \& Aarden LA (1989) Increased plasma levels of interleukin-6 in sepsis. Blood 74, 1704-1710.

44. Watanabe E, Hirasawa H, Oda S, Matsuda K, Hatano M \& Tokuhisa T (2005) Extremely high interleukin-6 blood levels and outcome in the critically ill are associated with tumor necrosis factor- and interleukin-1-related gene polymorphisms. Crit Care Med 33, 89-97.

45. Cuzzocrea S, Mazzon E, EDi Paola R, Esposito E, Macarthur H, Matuschak GM \& Salvemini D (2006) A role for nitric oxidemediated peroxynitrite formation in a model of endotoxininduced shock. J Pharmacol Exp Ther 319, 73-81.

46. Sener G, Toklu H, Kapucu C, Ercan F, Erkanli G, Kaçmaz A, Tilki M \& Yegen BC (2005) Melatonin protects against oxidative organ injury in a rat model of sepsis. Surg Today 35, $52-59$. 
47. Cuzzocrea S, McDonald MC, Mazzon E, Dugo L, Lepore V, Fonti MT, Ciccolo A, Terranova ML, Caputi AP \& Thiemermann C (2000) Tempol, a membrane-permeable radical scavenger, reduces dinitrobenzene sulfonic acid-induced colitis. Eur J Pharmacol 406, 127-137.

48. Besselink MG, van Santvoort HC, Buskens E, et al. (2008) Probiotic prophylaxis in predicted severe acute pancreatitis: a randomised, double-blind, placebo-controlled trial. Lancet 371, 651-659.

49. Anukam KC, Osazuwa EO, Osadolor HB, Bruce AW \& Reid G (2008) Yogurt containing probiotic Lactobacillus rhamnosus
GR-1 and L. reuteri RC-14 helps resolve moderate diarrhea and increases CD4 count in HIV/AIDS patients. J Clin Gastroenterol 42, 239-243.

50. Trois L, Cardoso EM \& Miura E (2008) Use of probiotics in HIV-infected children: a randomized double-blind controlled study. J Trop Pediatr 54, 19-24.

51. Bibiloni R, Fedorak RN, Tannock GW, Madsen KL, Gionchetti P, Campieri M, De Simone C \& Sartor RB (2005) VSL\#3 probioticmixture induces remission in patients with active ulcerative colitis. Am J Gastroenterol 100, 1539-1546. 